\title{
Intragluteal Hydatid Cyst: Report of a Case
}

\section{Derici Serhan ${ }^{1 *}$ and Sokmen Selman²}

${ }^{1}$ Attendant in General Surgery, Department of Surgery, School of Medicine, Dokuz Eylul University, Turkey

${ }^{2}$ Professor of Colorectal and Pelvic Surgery, Department of Surgery, School of Medicine, Dokuz Eylul University, Turkey

\section{Case Report}

A 40-year-old woman living in Mediterranean region was admitted to the hospital because of a slowly growing painfull mass in her right gluteal region. She had no complaint but a sense of dull pain and a mass lesion. In past medical history a surgical procedure ("unroofing") was performed for liver echinococcosis 14 years ago. The patient was treated with albendazole ( $400 \mathrm{mg}$ daily) for 12 months. On physical examination, a tense and smooth-surfaced, deeply situated cystic tumoral lesion, $4.0 \times 6.0 \mathrm{~cm}$ in diameter was palpated in the upper lateral part of the right gluteal region. Indirect hemagglutination assay (a cutoff titer of 1:160) and enzyme-linked immunosorbent assay (ELISA) were tested positive. Pelvic Computerized Tomography (CT) showed a large, hypodense multilobular cystic mass which was filled with several septae and cysts in the right gluteus maximus muscle (Figure 1). The provisional diagnosis was secondary echinococcal cyst of the gluteus muscle. We decided to obtain $\mathrm{CT}$ of the thoracoabdominal region to search for recurrent liver echinococcosis and/or secondary echinococcosis of lung. Abdominal CT only showed postoperative changes in liver segment $4 \mathrm{~A}$ (Figure 2). No cystic echinococcosis was detected in the lungs. Preoperatively albendazole $(10 \mathrm{mg} / \mathrm{kg} / \mathrm{daily})$ was given for 1 month. In the surgical exploration a chain of cystic masses were found deeply located in the gluteus muscle. A string of hydatid cysts, like "a string of beads", surrounded by a thick fibrous capsule were adhered to the deeper parts of gluteus muscle. After blunt and sharp meticulous dissection the hydatid cysts were completely removed en-block without cystic rupture and spillage inadvertantly (Figure 3). Histological examination was revealed the echinococcosis of gluteus muscle. Postoperative period was uneventful and a supplementary chemotherapy with albendazole $(10 \mathrm{mg} / \mathrm{kg} /$ daily $)$ for a six-month course was recommended. There was no evidence of local and/or distant recurrence of primary and secondary hydatid disease at eighteen months follow-up period.

\section{Discussion}

Muscular hydatidosis, being rare, must be kept in mind in the differential diagnosis of soft tissue swellings in order to prevent rupture, infection, anaphylaxis and recurrence of the cysts. It has been suggested that muscle provides a poor environment for the parasite because of the presence of lactic acid [1]. The volume of the gluteal muscle mass and its rich blood supply could explain the exceptional nature of this localization in our patient.

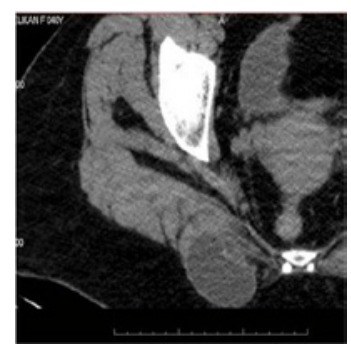

Figure 1: A CT scan demonstrated a low-density multilobular cystic mass with several septae extending into the deeper parts of the gluteus muscle.

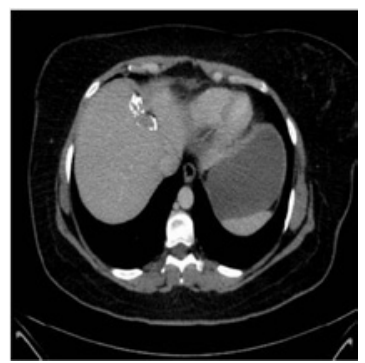

Figure 2: Postoperative changes in $4 \mathrm{~A}$ liver segment due to prior hydatid disease surgery.
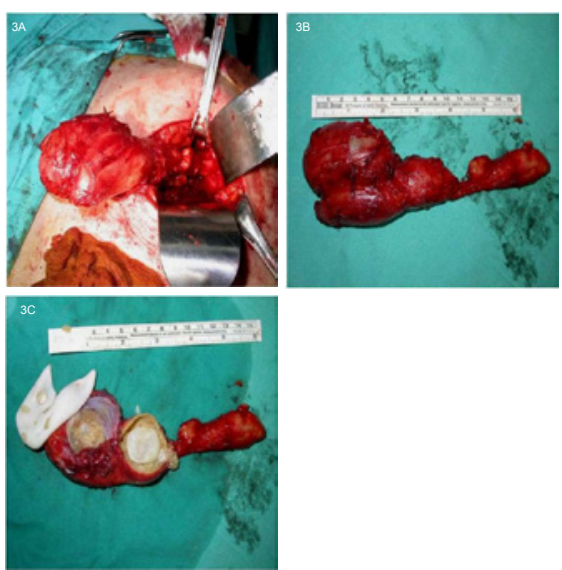

Figure 3: A) A string of cystic masses with cordon-like bands in-between which were adhered to the deeper parts of gluteus muscle. B) Multiple hydatid cystic lesions were seen after a thick fibrous capsule dissected. C) The cyst wall consists of a syncitial germinal layer which gives rise to daughter cysts.

Imaging modalities such as ultrasound and CT may reveal a welldefined cystic lesion with daughter cysts, containing septae or debris in it [2]. The value of these diagnostic tests is now extended to following up after chemotherapeutic or surgical approach and provides a visual guidance for needle aspiration of cyst contents for diagnosing clinically suspected cases of echinococcosis and in treatment by puncture and aspiration [3]. Serological tests may aid in the diagnosis but are usually not positive in all cases [4].

The treatment of muscle echinococcosis is a combined modality

*Corresponding author: Derici Serhan, Attendant in General Surgery, Department of Surgery, School of Medicine, Dokuz Eylul University, Inciraltı, Izmir 35340, Turkey, E-mail: serhanderici@gmail.com

Received January 20, 2012; Accepted March 17, 2012; Published March 24 2012

Citation: Serhan D, Selman S (2012) Intragluteal Hydatid Cyst: Report of a Case J Clinic Case Reports 2:115. doi:10.4172/2165-7920.1000115

Copyright: (C) 2012 Serhan D, et al. This is an open-access article distributed under the terms of the Creative Commons Attribution License, which permits unrestricted use, distribution, and reproduction in any medium, provided the original author and source are credited. 
of anti-helmintic chemotherapy and surgery, with total excision of the cystic lesion from adjacent muscle $[2,4,5]$. Albendazole has been found to be more useful in treating this lesion [6]. Meticulous surgical technique is so important to avoid inappropriate cyst rupture with the attendant risks of local contamination and metastatic dissemination to other organs.

\section{References}

1. Garcia-Diez Al, Ros Mendoza LH, Villacampa VM, Cozar M, Fuertes MI (2000) MRI evaluation of soft tissue hydatid disease. Eur Radiol 10: 462-466.

2. Haque F, Harris SH, Khan R, Abbas SZ (2006) Primary hydatidosis of gluteus maximus. J Postgrad Med 52: 300-301.
3. Geller DA, Goss JA, Tsung A (2010) Liver. In: Schwartz's Principles of Surgery. Brunicardi FC, Andersen DK, Billiar TR, et al. 9th ed. New York: McGraw Hill, pp. 1116.

4. Combalia A, Sastre-Solsona S (2005) Hydatid cyst of gluteus muscle. Two cases. Review of the literature. Joint Bone Spine 72: 430-432.

5. Chiattoni MK, Jorge V, Jannke HA, Telo GH, Segala NC (2003) Intramuscular hydatid cyst: a case report. Rev Soc Bras Med Trop 36: 527-529.

6. Morris DL, Dykes PW, Marriner S, Bogan J, Burrows F, et al. (1985) Albendazole-objective evidence of response in human hydatid disease. JAMA 253: 2053-2057. 